\title{
Research on Hierarchical Interactive Teaching Model Based on Naive Bayesian Classification
}

\author{
Dongyan Fan \\ Information faculty, Business College of Shanxi University, Taiyuan 030031, China
}

\begin{abstract}
The purpose of this research is improving the current inject classroom teaching mode that ignores individual differences and inefficiency of students. By studying classification algorithm in data mining and applying the classification method based on Naive Bayes algorithm, we designed and implemented scientific classification of students, and draw lessons from stratified and interactive teaching mode, so as to builded a new effective teaching mode. The results show that through scientific classification of students, real-time hierarchical interaction teaching effectively stimulate students' interest in learning, improve cooperation ability, and improve classroom teaching efficiency.
\end{abstract}

Keywords-Naive Bayesian; student classification; hierarchical interactive; teaching model

\section{INTRODUCTION}

Under the background of big data era, the current teaching mode is not adapt to the cultivation of innovative talents, there are many problems, such as low efficiency of classroom, teachers' manipulation of teaching process, ignore the individual differences of students in knowledge transfer ability. Therefore, this study aimed at these problems, by studying classification algorithm in data mining and applying the classification method based on Naive Bayes algorithm, we design and implement scientific classification of students, and draw lessons from stratified and interactive teaching mode, so as to build a new effective teaching mode. The mode enable students to learn efficiently, so as to adapt to the trend of rapid development of new technology and cultivate innovative talents.

\section{RESEARCH METHOD}

The research and practice of the hierarchical interactive teaching model based on the Naive Bayesian classification is based on the classification of students' differences. So there are two major tasks need to do: the approaches to the students' difference measurement and grouping and the design of hierarchical interactive teaching framework. Its method flow is shown in Figure I.

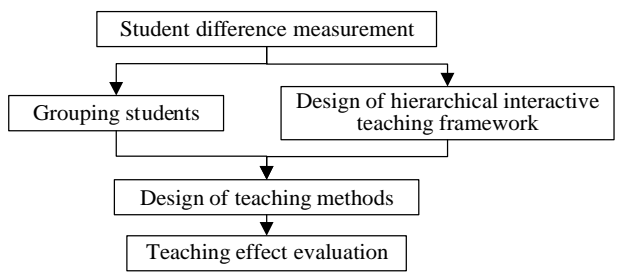

FIGURE I. RESEARCH METHOD FLOW
First of all, based on the samples, the naive Bayes algorithm according to the student's attribute value is used to test the students' differences. Then, according to the results to make a scientific difference classification to achieve effective grouping for students. At the same time, the design of the hierarchical interactive teaching framework is carried out by the two subjects (the student is the main body, the teacher is the leading part). Finally, the teaching effect is evaluated and analyzed.

\section{StUdent ClassificAtion Design BASED On NAIVE BAYESIAN}

\section{A. Naive Bayesian Theoretical Principle}

At present, there are many kinds of algorithms in data mining, such as based on Bayes algorithm, decision tree algorithm, neural network algorithm, rough set algorithm, genetic algorithm, support vector machine algorithm and so on. In the practical application of many classification algorithms, the most widely used algorithm is Naive Bayesian algorithm model. Naive Bayes is a simple and effective classification model.From Bayes' theorem recall that:

$$
P(B \mid A)=\frac{P(A \mid B) P(B)}{P(A)}
$$

Equation (1): $P(A)$ and $P(B)$ separate representation the probability of occurrenceof events $A$ andevents $B$.

$P(A \mid B)$ indicates the probability of occurrence of event A under the premise that event $\mathrm{B}$ occurs. $P(A \mid B)$ is a priori probability, and its value is often easily obtained.

$P(B \mid A)$ indicates the probability of occurrence of event $B$ under the premise that event $A$ occurs. $P(B \mid A)$ is a posteriori probability, and its value is the result of the solution of the Bayesian formula.

The classifier structure diagram based on the naive Bayes algorithm is shown in Figure II. It's leaf node Am represents the $\mathrm{m}$ attribute, and the root node $\mathrm{C}$ represents the category. Suppose $D=\{C, A, S\}$ are training samples, it includes the student category $C=\left\{C_{1}, C_{2}, \cdots C_{i}\right\}$ and the student attribute $A=\left\{A_{1}, A_{2}, \cdots A_{m}\right\}$.Suppose $S=\left\{S_{1}, S_{2}, \cdots S_{n}\right\}$ represents a collection of classified students, in which $S_{n}$ represents nth student. Suppose $X_{k}=\left\{a_{1}, a_{2}, \cdots a_{m}\right\}$ is a student to be classified, 
in which each $a_{m}$ represents an attribute eigenvalue of the pending item $X_{k}$.

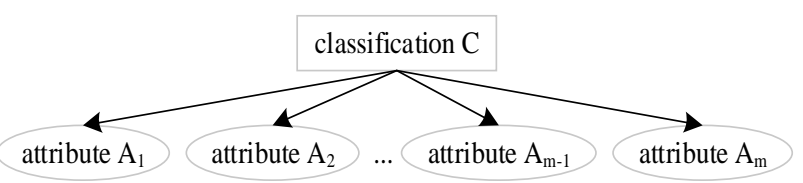

FIGURE II. THE CLASSIFIER STRUCTURE DIAGRAM

\section{B. Design the Individualized Attributes of Students}

The student classification method based on the naive Bayes algorithm is used the information of the past students as the sample set, which is used to construct the naive Bayes classifier.
Students are classified according to the information of the students' attributes. The students divided into the same category are not simply using the score as criterion of evaluation. Its are classified by comprehensive evaluation after combination of other attributes.

The difference classification based on the naive Bayes algorithm is select the individual attributes of the students as shown in Figure III. The students which 8 attribute values similar in the two dimensions (character and learning style) are put into one category, while the 12 attributes values of the three dimensions of personal basic situation, learning interest and cognitive ability are different. The purpose of the classification is to carry out differential teaching to implicit dynamic stratification and heterogeneous cooperation for students' cognitive ability, learning interest and basic information.

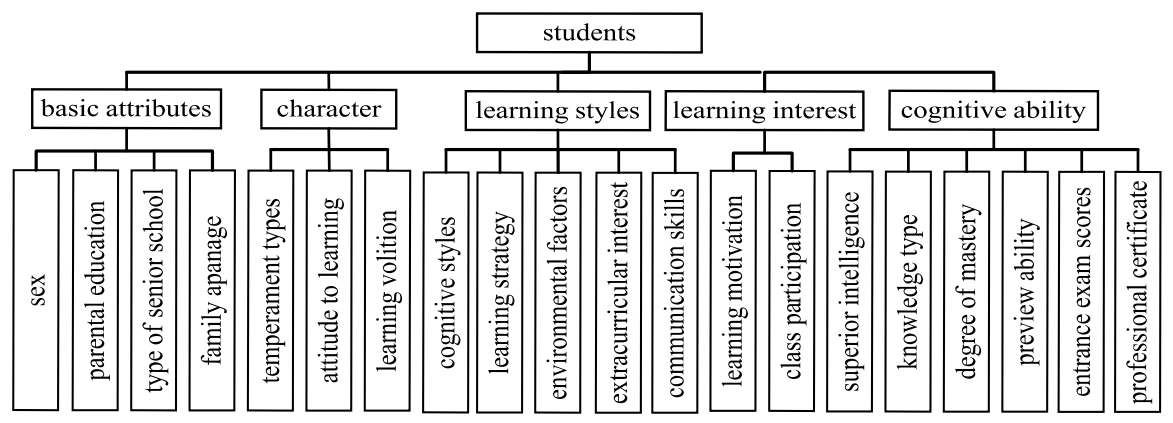

FIGURE III. INDIVIDUALIZED ATTRIBUTES OF STUDENTS

\section{Student Classification Design Based on Naive Bayesian}

The process based on the naive Bayes classification is shown in Figure IV.

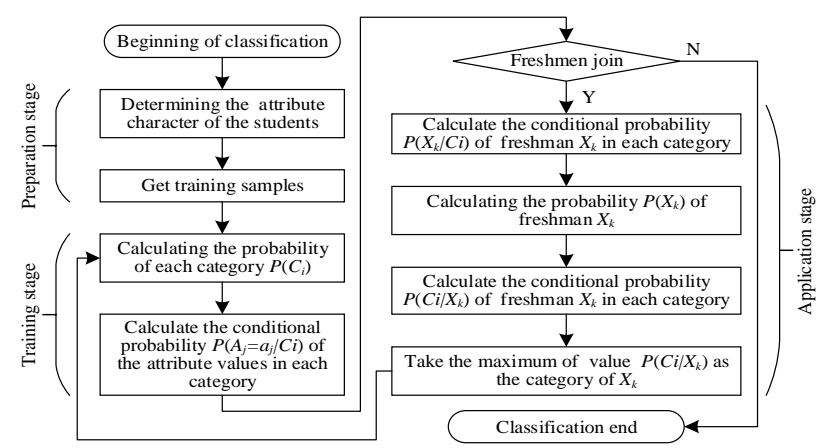

FIGURE IV. STUDENT CLASSIFICATION CYCLE FLOW CHART BASED ON NAIVE BAYES ALGORITHM

1) $P\left(C_{i}\right)$ is set to indicate the frequency of the occurrence of the student category $C_{i}$ in the training sample concentration, that is the category probability. For sample data sets, there are different levels of students in each category, which avoids the discrimination of students.

$$
P\left(C_{i}\right)=\frac{\operatorname{Count}\left(C_{i}\right)}{n}
$$

The function Count $\left(C_{i}\right)$ represents the number of students belonging to category $i$ which is in the entire student sample collection of $S . n$ represents the total number of the entire student sample collection of $S$.

2) $P\left(A_{j}=a_{j} \mid C_{i}\right)$ is set to represent the conditional probability of each characteristic attribute value of the student in the category.

$$
P\left(A_{j}=a_{j} \mid C_{i}\right)=\frac{\operatorname{Count}_{C_{i}}\left(A_{j}=a_{j}\right)}{\operatorname{Count}\left(C_{i}\right)}
$$

$A_{j}=a_{j}$ indicates that the value of the $j$ attribute is $a_{j}$.The function $\operatorname{Count}_{C_{i}}\left(A_{j}=a_{j}\right)$ represents the number of students which the attribute name is $A_{j}$ and attribute value is $a_{j}$ in the $i$ student category.

3) $P\left(X_{k} \mid C_{i}\right)$ is set to represent the conditional probability of the students $X_{k}$ to be classified in the student category $C_{i}, m$ represents the number of attributes that describe student differences.

$$
P\left(X_{k} \mid C_{i}\right)=\prod_{j=1}^{m} P\left(A_{j}=a_{j} \mid C_{i}\right)
$$


4) $P\left(A_{j}=a_{j}\right)$ is set to represent the probability of the student's attribute $A_{j}$ when the value is $a_{j}$.

$$
P\left(A_{j}=a_{j}\right)=\frac{\operatorname{Count}\left(A_{j}=a_{j}\right)}{n}
$$

The function Count $\left(A_{j}=a_{j}\right)$ indicates the number when the value of attribute $j$ is $a_{j}$.

5) $P\left(X_{k}\right)$ is set to indicate the probability that the student $X_{k}$ should be classified in the training sample concentration.

$$
P\left(X_{k}\right)=\prod_{j=1}^{m} P\left(A_{j}=a_{j}\right)
$$

6) $P\left(C_{i} \mid X_{k}\right)$ is set to represent the conditional probability that the student $X_{k}$ should be classified to category $i$.

$$
P\left(C_{i} \mid X_{k}\right)=\frac{P\left(X_{k} \mid C_{i}\right) P\left(C_{i}\right)}{P\left(X_{k}\right)}
$$

7) $P\left(C_{\max } \mid X_{k}\right)$ is set to represent the maximum category probability of the student $X_{k}$ which should be classified to the student category .

$$
P\left(C_{\max } \mid X_{k}\right)=\max \left\{P\left(C_{1} \mid X_{k}\right), P\left(C_{2} \mid X_{k}\right), \ldots, P\left(C_{i} \mid X_{k}\right)\right\}
$$

$C_{\max }$ indicates the maximum category of conditional probability which is obtained by (8).

Finally, (8) is used to calculate the maximum category probability of the students to be classified in the students category. That is the category of the students to be classified. At this point, one classification ends.

\section{The Design of the Hierarchical INTERACTIVE TEACHING FRAMEWORK}

The hierarchical interactive teaching model is an independent, inquiring and cooperative teaching model based on the classification of the naive Bayes algorithm. This model breaks the original classroom structure, and takes the interaction of teachers and students as the carrier, and also group autonomy, and let the students as the subject of the class. This model is guided by the task of the problem, and it is based on the students' self-study, and it aims at the completion of the task of the group. This model creates an ecological chain class based on group mutual learning to solve problems. It pays attention to the state of learning and the quality of life for every student. The design of the hierarchical interactive teaching model framework is shown in Figure V.

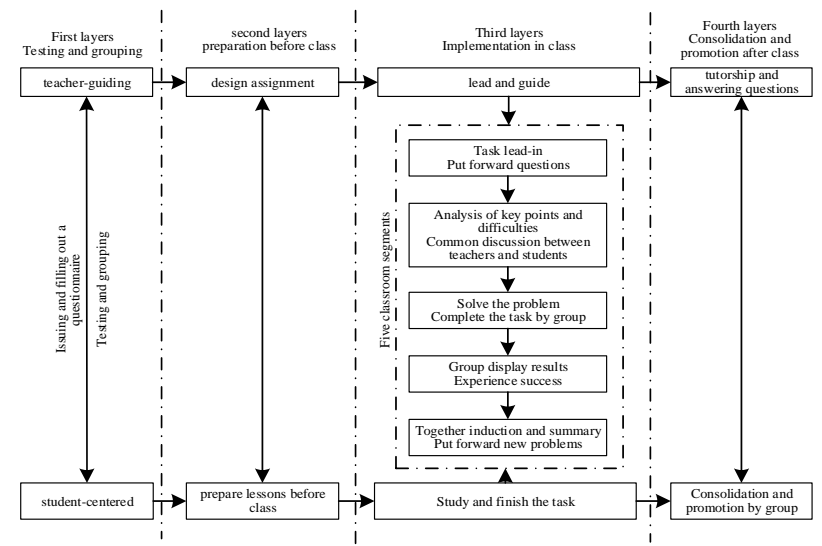

FIGURE V. THE HIERARCHICAL INTERACTIVE TEACHING MODEL FRAMEWORK

The four layers of the hierarchical interactive teaching model are closely related to each other, and support each other dynamically with the spiral. The five segments drive each other to form a whole, interlace and connect with each other. This teaching mode makes the classroom an active area for teachers and students to resonate with their ideology and to show their personality together.

\section{ANALYSIS OF TEACHING EFFECT}

In this paper, the teaching effect is analyzed from two aspects by using the method of questionnaire and comparative experiment. First, the experimental class's comparative analysis before and after the experiment is carried out. Then, a comparative analysis between the experimental class and the contrast class is carried out.

The comparative data of the experimental class before and after the experiment are shown in Figure VI. From Figure VI, it can be seen that $85.72 \%$ of the students have An attitude of approval towards the application of the hierarchical interactive teaching model based on the naive Bayes algorithm in the teaching. There are $70.13 \%$ of the students satisfied with the improved teaching effect. At the same time, it can be seen that the students' interest in learning and the ability to communicate and cooperate have improved obviously. 


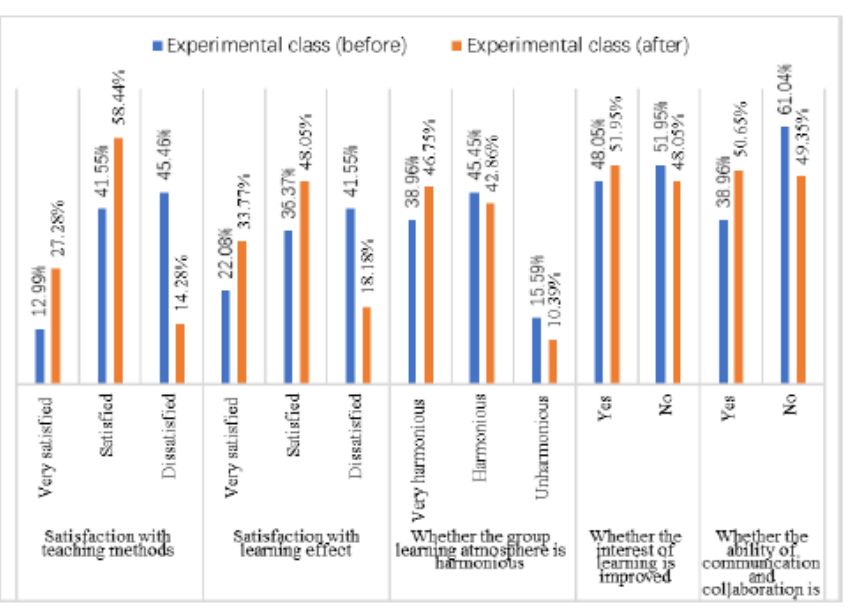

FIGURE VI. THE COMPARATIVE DATA OF THE EXPERIMENTAL CLASS BEFORE AND AFTER THE EXPERIMENT

The comparison between the experimental class and the contrast class is shown in Figure VII. From Figure VII, we can see that students' satisfaction degree, teaching effect satisfaction and group learning atmosphere based on Naive Bayes algorithm classification are higher than those of the contrast class. At the same time, it can be seen that the students' interest in learning and the ability to communicate and cooperate have also been improved.

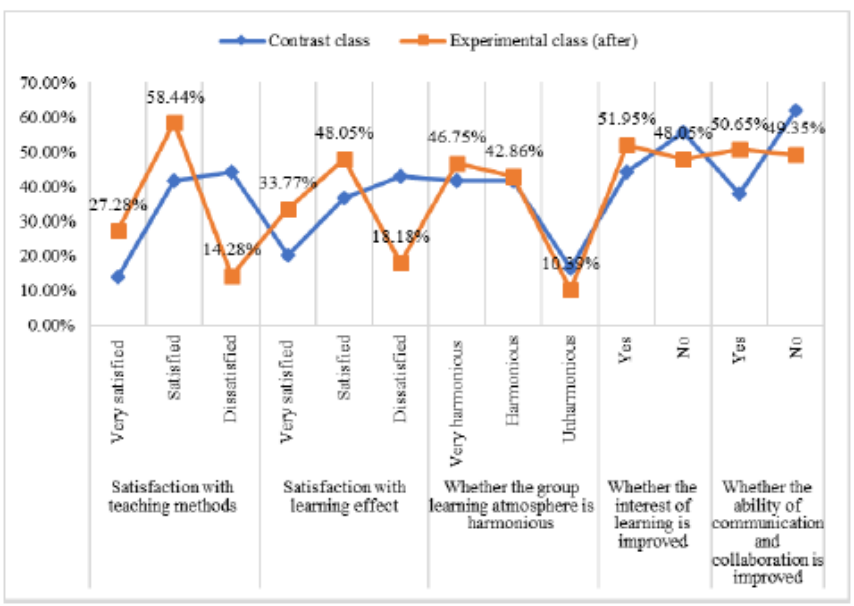

FIGURE VII. THE COMPARISON BETWEEN THE EXPERIMENTAL CLASS AND THE CONTRAST CLASS

\section{CONCLUSION}

The comprehensive analysis shows that, in the implementation of the hierarchical interactive teaching model based on the naive Bayes algorithm, the new teaching mode was accepted by the students, it was welcomed by the students. The new teaching mode can improve the ability of learning interest and collaboration of students. It has a very good teaching effect. Experiments show that the classification algorithm based on Naive Bayes has better feasibility and effectiveness in solving student classification problem.

However, due to the limited personal time and ability, there are still some shortcomings in the study. In order to better achieve hierarchical interaction teaching mode based on Naive
Bayes algorithm and improve teaching effect, we still need to further improve the limitation of applying naive Bayes algorithm, that is, suppose the attributes of students are independent.

\section{ACKNOWLEDGMENT}

This work was supported by "Research and construction of the practice teaching system of information specialty(J2016138, The major project of teaching reform research in Shanxi Education Department)" and "The optimization and the platform construction of the practice teaching system of information specialty (SYJ201509, The major project of the research on teaching reform Business College of Shanxi University)”. Our special thanks are due to Prof. Ma Shangcai, for his helpful discussion with preparing the manuscript.

\section{REFERENCES}

[1] Jonathan Rauh. Problems in Identifying Public and Private Organizations: A Demonstration Using a Simple Naive Bayesian Classification[J]. Public Organization Review,2015,15(1).

[2] SangitaB, P., Deshmukh, S.R.. Use of Support Vector Machine, decision tree and Naive Bayesian techniques for wind speed classification[P]. Power and Energy Systems (ICPS), 2011 International Conference on,2011.

[3] Yan Dong. Hierarchical interactive teaching mode and its practice and exploration of mathematics teaching in Senior High School [D]. Southwest University,2016.

[4] Chen Zhiqiang. Hierarchical interactive teaching mode and its practice and exploration of mathematics teaching in Senior High School [D]. Henan University,2016.

[5] S. Mukherjee and N. Sharma. Intrusion detection using naïve Bayes classifier with feature reduction[J].Procedia Technology,vol. 4, pp. 119128, 2012.

[6] L. Jiang, Z. Cai, D. Wang, and H. Zhang. Improving tree augmented naive Bayes for class probability estimation[J]. Knowledge-Based Systems, vol. 26, pp. 239-245, 2012.

[7] Sharma RK, Sugumaran V, Kumar H, Amarnath M. A comparative study of naïve Bayes classifier and Bayes net classifier for fault diagnosis of roller bearing using sound signal[J].International Journal of Decision Support Systems. 2015 Jan 1; 1(1):115-29.

[8] Hamse Y Mussa, John BO Mitchell,Robert C Glen.Full "Laplacianised" posterior naïve Bayesian algorithm[J]. Journal of Cheminformatics. 2013 5:37.

[9] K. Magesh Kumar, P. Valarmathie. Domain and Intelligence Based Multimedia Question Answering System[J]. International Journal of Evaluation and Research in Education, Vol. 5, No. 3, September 2016 : $227-234$

[10] [11]Zhijun Wang1, Li Chen, Terry Anderson. A Framework for Interaction and Cognitive Engagement in Connectivist Learning Contexts[J]. International Review of Research in Open and Distance Learning, Vol. 15,No.2, Apr 2014:121-141. 